ISSN1027-5495. Functional Materials, 24, No.3 (2017), p. 442-450

\title{
The novel method for LAI inversion using Lidar and hyperspectral data
}

\author{
Zuowei Huang ${ }^{1}$, Feng Liu $^{2}$,Guangwei $\mathrm{Hu}^{1}$ \\ ${ }^{1}$ School of Architecture and urban planning, Hunan University \\ of Technology, Zhuzhou 412008,China \\ ${ }^{2}$ School of Geosciences and Information-Physics,Central South \\ University,Changsha 410083,China
}

\section{Received January 25, 2017}

\begin{abstract}
For inversion of Leaf area index (LAI) in large scale, it is of great significance to integrate space-borne Lidar and optical remote sensing data effectively. In order to improve the estimation precision of leaf area index, an analyzing method based on Lidar and hyperspectral data was proposed. Through the processing of Lidar (Light Identification Detection and Ranging) and hyperspectral data, the LAI estimation model was established based on statistic analysis method in the study area. The results showed that the Lidar and hyperspectral data joint inversion model which considers the optical remote sensing of biophysical parameters can provide good estimates of LAI inversion, shows high accuracy $\left(\mathrm{R}^{2}=0.8948, \mathrm{RMSE}=0.2120\right)$, which reveals the great potential to enhance the accuracy of LAI estimation by using Lidar and hyperspectral
\end{abstract} data.

Keywords: LAI, Lidar, Hyperspectral data, Spectral unmixing, data inversion

В целях повышения точности оценки индекса площади листа (LAI) был предложен метод анализа, основанный на лидарных и гиперспектральных данных. Посредством обработки LIDAR данных и гиперспектральных данных была разработана модель оценки LAI на основе метода статистического анализа. Результаты показали, что модель инверсии совместных данных LIDAR и гиперспектральных данных, которая учитывает оптическое дистанционное зондирование биофизических параметров, может обеспечить хорошие оценки инверсии LAI и обеспечивает высокую точность $\left(\mathrm{R}^{2}=0,8948, \mathrm{RMSE}=0,2120\right)$. Данная методика показывает возможности для улучшения точности оценки LAI с использованием LIDAR гиперспектральных данных.

Новий метод оцінки індексу площі листа 3 використанням лідальних та гіперспектральних даних. Zuowei Huang, Feng Liu,Guangwei Hu

В цілях підвищення точності оцінки індексу площі листа (LAI) запропонувався метод аналізу, який базується на лідальних та гіперспектральних даних. За допомогою обробки LIDAR даних і гіперспектральних даних була розроблена модель оцінки LAI на основі методу статистичного аналізу. Результати показали, що модель інверсії спільних даних LIDAR і гіперспектральних даних, яка враховуе оптичне дистанційне зондування біофізичних параметрів, може забезпечити хороші оцінки інверсії LAI, забезпечуе високу точність $\left(\mathrm{R}^{2}=0,8948, \mathrm{RMSE}=0,2120\right)$. Дана методика показуе можливості для поліпшення точності оцінки LAI з використанням LIDAR гіперспектральних даних. 


\section{Introduction}

As we all know, The forest resource is one of the most important natural resources, and plays an important role in the sustainable development of mankind [1]. Leaf area index (LAI) is defined as the single-side leaf area per unit ground area, which is an important biological parameter reflecting crop growing, providing structured quantitative information for describing the procedure of matter and energy exchange on plant canopy surface $[2,3]$.

Light Detection And Ranging (LIDAR) is a new emerging active remote sensing technology in recent years, which has developed very rapidly in the world. Lidar can measure both the vertical and horizontal structure of forested areas effectively with high precision and it can accurately estimate tree height, canopy closure and above-ground biomass [4,5]. Considering their ultra narrowband design, the spectral responses of hyperspectral sensors are more sensitive than wide-band multi-spectral data, thus enabling the efficient estimation of canopy biophysical parameters and chemical parameters well, Therefore, these sensors can be successfully used for LAI inversion[6-8].Considering the topography and complex canopy characteristics of high-coverage forests,tree species mapping using optical remote sensing data remains difficult [9-10]. The traditional methods of forest parameters measurement have some limitations in large scale. Due to the direct measurement capability with high precision on the forest vertical structure.Lidar technology shows unsurpassed advantages in the measurement over this parameters [11]. Lidar sensor measures a target by actively transmitting an electromagnetic wave of a certain wavelength. These signals can penetrate the leaves of a canopy as well as tree trunks to reach the ground. The sensor receives a certain amount of light through reflection and scattering [12,13].The distance from the sensor to ground samples can be calculated by measuring the time delay between the laser return pulses of the ground samples relative to the main wave to measure the surface fluctuation, and then obtain the vertical information of it [14]. Therefore,Lidar data are often used for the inversion of forest vertical structural information in forestry [15].

One of the most significant issues in remote sensing image processing fields is developing methods for dealing with mixed pixels [16]. Meanwhile, in many remotely sensed image application fields, land surface parameters are needed to be estimated in the sub-pixel level [17]. However, due to the limitations of spatial resolution and the complexity and diversity of the various types of surface features, images,

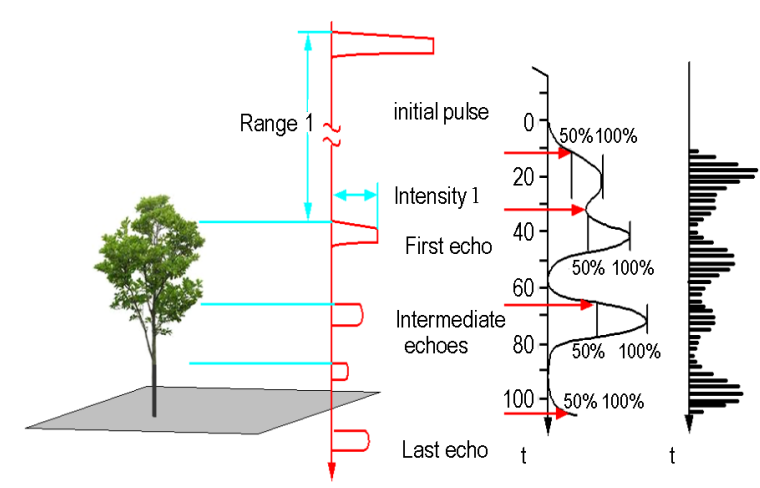

Fig.1 The schematic diagram of multi-echo and full waveform

in addition to pure pixel, there may exist a mixture that contains a variety of surface features pixel, and thus can not achieve the accuracy of remote sensing applications [18]. Endmember extraction is the most important and complicated procedure in spectral unmixing especially. Spectral unmixing can acuqire the appropriate endmembers and abundances according to minimizing the Residual Sum of Squares [19].

Based on the physical structure of the ground component, this study developed the linear mixture model for LAI estimation. It could not only deal with the difficulty of Spectral discrimination (such as "the same thing with different spectrum, and the same spectrum but different thing"), but also was simple, feasible, and general [20]. Two main methods which establish the relationships between LAI and satellite observed spectral canopy reflectance are widely used for LAI retrieval from remote sensing data, including vegetation indexbased empirical regression method and physical model-based method [21,22] .Lefsky, et al. (2001) pointed out that in spite of the laser radar being sample data, it will greatly enhance the forestry measurement by integrating other grid remote sensing data owing to the very high precision [23].

\section{Study Method}

\subsection{Theoretical principle of LAI}

Lidar launches a pulse in a short time. When meeting obstacles, the pluse will return. If the return energy is larger than the threshold of the system, the system will record it as one point. Point cloud intensity is influenced by many factors, such as reflectance of the target, target-sensor distance, scanning zenith angle, and atmospheric condition. The base principle is shown in Fig.1, (a) is multiple echo of point cloud. Fig.1 (b) is full waveform diagram. Fig. 1 (c) is digital waveform diagrams.Relative to the discrete point cloud data, the waveform 
data can stored all the echoes returned laser pulses, which play an increasingly important role in the later analysis.

In order to evaluate the precision of leaf area index (LAI), reflectance data were collected with ASD at two sampling sites, vegetation indices were applied to regress against LAI, canopy reflectance were transformed with wavelet analysis, and extracted wavelet energy coefficient were applied in regression model for LAI estimation. transforming the point cloud into grid, when there have multiple points, using the max value as the pixel-value. then getting $0.8 \mathrm{~m}$ resolution DSM. After extracting valid waveforms data, smoothing filtering was realized by using a gauss filter which width was the same as the laser pulse width. The background noises in the beginning and end of phase were estimated using the histogram method (Sun,et al., 2008) and the features parameters (mean value and standard deviations) were also calculated. Then the waveform was fitted effectively by Levenberg Marquardt nonlinear method, and the wave peak position of the ground and forest canopy was determined by gauss wave decomposition (Dong, 2008)

The vertical structural information obtained by Lidar data, which helps in removing the interferences of forest gaps and other non-forest pixels as well as in extracting the canopy subsets. In addition, training samples can be easily extracted at a certain tree height of different species in the spectrum space. Therefore, based on the canopy subsets as well as the combined spectral differential and curve matching techniques, an automatic extraction method of training samples is realized. DEM is generated using TIN interpolation method with the ground point data classified. Then, the elevation values of vegetation points are normalized by DEM to remove the terrain elevation, so that the height values of vegetation points are the heights relative to the ground.

\subsection{Mixed pixel decomposition}

Mixed pixel decomposition is the most effective method to solve the mixed pixel problem, LSMM is one of the mixed decomposition model that been applied most extensively,it mainly includes four parts (Fig.2): Data Preprocessing, Endmember Extraction, Abundance Estimation and Accuracy Assessment, which can be described as by using linear mixed model:

$$
x=\sum_{i=1}^{p} A_{i} S_{i}+\varepsilon=A S+\varepsilon
$$

where $p$ is the number of the endmembers, $\mathrm{A}$ is the endmember matrix of $n \times m$, its every column is endmember vector of image, called endmember spectral set, $\mathrm{S}$ is the component ratio

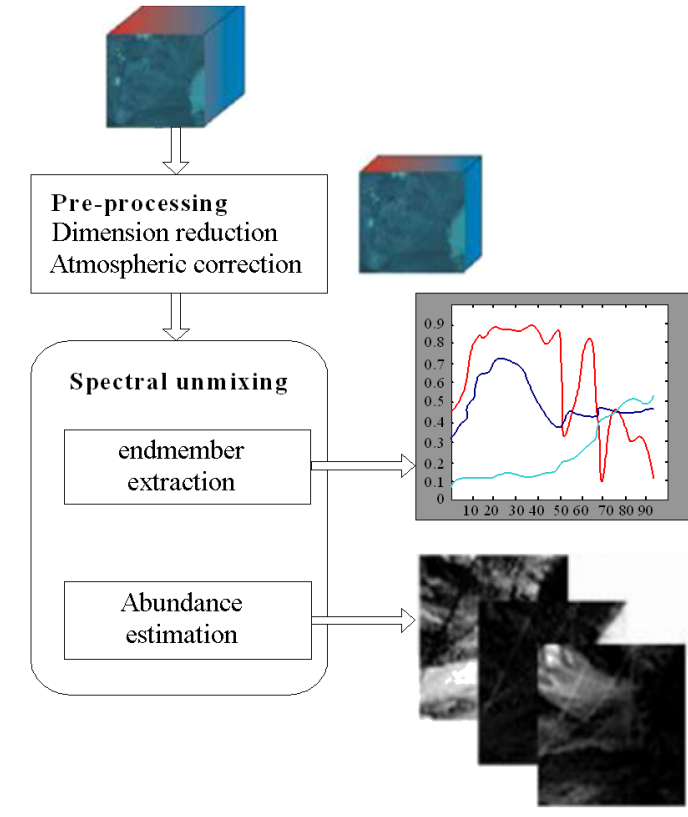

Fig.2. The processing of Mixed pixel decomposition

of endmember composition for every pixel, Ai and $\mathrm{Si}$ is the $i$-th endmember and mixing proportion, respectively, and $\varepsilon$ represents the random noise term. In terms of the physical significance, Eq.(1) expresses that in hyperspectral image, any pixel vector can be expressed as a combination of $\mathrm{n}$-dimension component ratio by $n$-dimension endmember vector, its mathematical meaning is a product of matrix A consisting of $\mathrm{m} \mathrm{Y} n$ dimension endmember vector and vector $\mathrm{s}$ consisting of $\mathrm{m}$-dimension component ratio. There are two constraints for the abundance vector : non-negativity constraints (ANC, Abundance Non negativity Constraint, $s_{i} \geq 0$, $i=1,2, \ldots, p)$ and as a Constraint.

How to dynamically optimize endmember spectral set A needs to solve three problems: (1) Confirm the principle ofthe most probable vector in image; (2) selecting the algorithm of the endmember vector; (3) Adaptively obtain the principle of the number of endmember vectors. The algorithm is shown as below:

1.Estimate or assign the number of endmembers within the image data: For a predefined number of endmember $p$, Using the dimension reduction methods, Principal Component Analysis (PCA) was applied on the original hyperspectral image data to reduce the dimensions from $N$ to $p-1$;

2. Exhaustion search: for any monomer is composed by pixel spectral vector (number $\mathrm{p}$ ), Select the pixels randomly as the initial endmembers, and calculate the simplex volume V1 that composed of these initial endmembers. The mathematical definition of the volume is :o 


$$
\begin{aligned}
& V\left(A_{1}, A_{2}, \ldots, A_{p}\right)= \\
& =\frac{1}{(p-1) !} \mid \operatorname{det}\left[\begin{array}{cccc}
1 & 1 & \ldots & 1 \\
A_{1}^{\prime} & A_{2}^{\prime} & \ldots & A_{p}^{\prime}
\end{array}\right]
\end{aligned}
$$

Where $A_{i}(i=1,2, \ldots p)$ is the $p-1$ dimensional column vector for the $i$-th endmember. Looking for the monomer volume biggest vector sets $\left\{A_{1}^{*}, A_{2}^{*}, \ldots, A_{p}^{*}\right\}$, its expression can be presented as below:

$$
\begin{aligned}
& \left\{A_{1}^{*}, A_{2}^{*}, \ldots, A_{p}^{*}\right\}= \\
& =\arg \left\{\begin{array}{c}
\max \\
\left\{A_{1}, A_{2}, \ldots, A_{p}\right\}
\end{array} V\left(A_{1}, A_{2}, \ldots, A_{p}\right)\right\}
\end{aligned}
$$

3. Estimating the candidate endmember set $\mathrm{E}$ at a certain probability level, Initialization the endmember by selecting $\mathrm{p}$ endmembers randomly from E; Evaluate an image pixel by replacing one pixel in the represent endmember set with the image pixel $\mathrm{P}_{1}$, producing a"trial enemember" set and calculate the new simplex volume $\mathrm{V}_{2}$. If $\mathrm{V}_{2}>\mathrm{V}_{1}$, replace the candidate enemember with $\mathrm{P}_{1}$ At $k^{\text {th }}$ iteration, calculating the volume of the simplex defined by the following formula using the estimated endmember.

4.Iterating for maximization the volume of the simplex, Replace the other candidate enemembers with the pixel P, Execute the procedures (2) and (3) for all the other pixels repeatedly The simplex volume composed of the result endmembers is the largest one, and its vertexes correspond to the endmembers. This process was repeated until no replacements were made.

The above method, which can eliminate the correlation between the bands of Hyperspectral Image and increase the quality of endmembers, was employed to convert the Hyperspectral Image into principal components. According to the relationship between vegetation cover percent and LAI, we can extract LAI from the remote sensing imagery successfully. Moreover, the canopy model of multiple scattering was applied to estimate the accurate LAI.

\section{Study area and data}

\subsection{Study area}

The study area is the Longhui district located near Shaoyang City (Fig.3), Hunan Province in China, $6.5 \mathrm{~km}$ from the city center, belongs to the low mountain hilly terrain, with a typical hilly landscape and a significant temperate continental monsoon climate. The climate in this region can be described as windy in spring, having high temperature and concentrated rainfall in summer, cool in autumn.

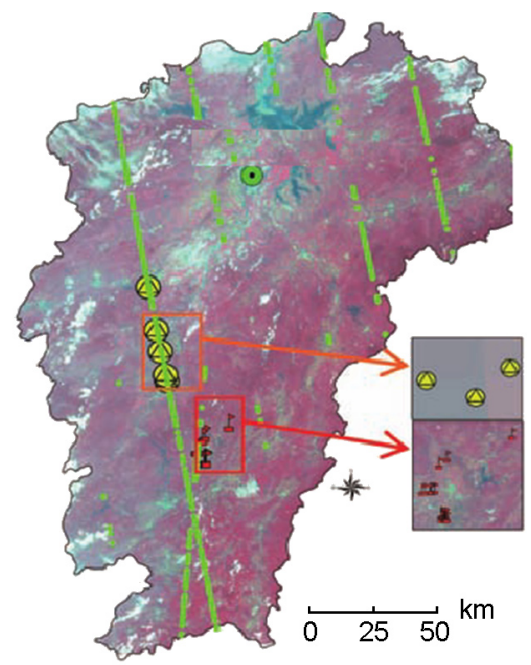

Fig.3. Research area and sampling sites

The altitude is about $260-550 \mathrm{~m}$, and annual average relative humidity is $80 \%$, The frostfree period reaches $310-330 d$. The study area is about $9648 \mathrm{Ha}$, Rich natural resources as well as complex and diverse vegetation community types are found in the region, which mainly composed of artificial forest and secondary natural forest. is dominated by red pine, Pinus sylvestris, Camellia oleifera, barley, and yellow pineapple, etc. Few roads stretching and residents living here. the spatial distribution of the crown structure has important significance in forestry, it using ground-based light detection points cloud for crowns in the field. Five sample areas of footprint in the study area were selected. Due to the foundations lidar instrument was heavily and hard to taken, these sample sites were all near the roads. Measurement was accomplished in two different directions (every $180^{\circ}$ ) in the $60 \mathrm{~m}$ Lidar footprint

\subsection{Data acquisition}

The Lidar data was acquired on May 31, 2015. The laser scanner is LiteMapper-5600, is developed by the German company IGI. with laser wavelength of $1550 \mathrm{~nm}$, and laser pulse length of $3.0 \mathrm{~ns}$, and laser beam divergence of $0.5 \mathrm{mrad}$. The hyperspectral data collected by the AVIRIS was acquired on August 23,2015 at the same district, it covers the spectral region from $0.4-2.5 \mu \mathrm{m}$ in 224 bands with a $10 \mathrm{~nm}$ band width and a $20 \mathrm{~m}$ spatial resolution. To improve the unmixing performance, we removed the low SNR bands, the abundance of the pixel in the data was created randomly, and in the meantime, the abundances of each pixel fulfill the ANC and ASC was replaced by the pixels whose maximum abundance was larger than 0.8 with a mixture made up of all endmembers of equal abundances. To simulate possible errors and 


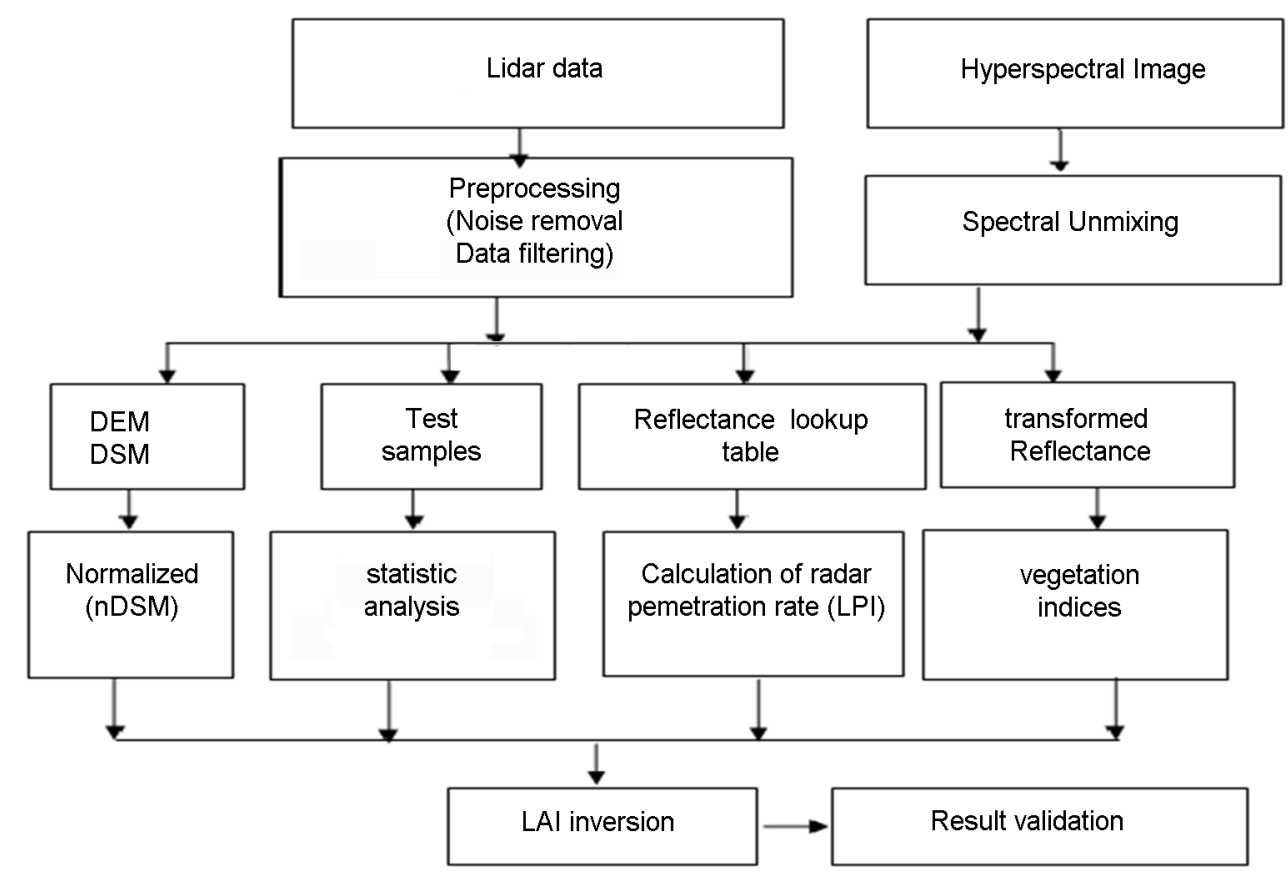

Fig.4 Data processing flow

sensor noise, it added zero-mean Gaussian noise to the mixture data. The image data was converted into the reflectance data using the ATREM method, the remnant error was minimized using the EFFORT method.

\subsection{Data processing}

Data processing flow is shown in Fig.4. Lidar data processing includes filtering classification, isolating laser surface topography subsets and distinguishing laser point data subsets of different features from the point cloud data. This paper separated ground and non-ground points from the point cloud product through filtering methods such as iteration, isolated points and threshold with a Terrascan. A Digital Elevation Model (DEM) was created by performing a Triangulated Irregular Network ( TIN) interpolation operation using the point cloud product that was already separated as ground points. point cloud data contain some noises, noise is commonly isolated points, it is detrimental for the subsequent inversion and it need to remove the noise points before processing. Noisy points can be divided into three categories according to their three-dimensional characteristics: isolated points are these points that no other point cloud points in their neighborhoods. Extreme high points, the Lidar points far higher from the nearby rough surface, usually caused by reflections of birds, low altitude airships or planes. Extreme low points, which are obviously lower than their adjacent ground Lidar points, are caused by multiple reflection of laser pulse or system errors. The existence of extreme low points can lead to significant errors when interpolating DEM or DSM , a Digital Surface Model ( DSM) was generated by interpolating the first return points. CHM elevation-normalized data were obtained by conducting a grid difference calculation between DSM and DEM.

Method for LAI acquisition uses the Yao method (Yao, et al., 2010). the DSM of laser point cloud in study area is get. According the forest growth, we chose the sample from the other fields with similar growth conditions, and then measured the leaf area by SunScan to determine LAI Each sample has precise GPS positioning data. SunScan does not wait for the special weather conditions and it can work properly in most light conditions. Hand-held terminal PDA is simple with large storage, which can meet the needs of large data measurement. Since the sensor using a wireless transmitting and receiving technology, it makes the measurement more convenient, quick access to the large area of forest region LAI. Wireless transmission range $250 \mathrm{~m}$, the vegetation coverage of 100 to $200 \mathrm{~m}$, greatly improve the efficiency of forest LAI. The aircraft attitude maintenance was supported using GPS equipment of aircraft navigation, inertial measure unit (IMU) and global positioning system (GPS) of airborne laser radar.GPS synchronous observation of high precision dynamic dual-frequency GPS receiver, the sampling frequency is $2 \mathrm{HZ}$. GPS base station within $10 \mathrm{~km}$ radius of the surface. The track amendment, the aircraft's pitch, the con- 
Table1. Correlation of LiDAR metrics and field measured LAI

\begin{tabular}{|c|c|c|c|c|c|c|c|c|c|}
\hline & LAI & $H_{50 t h}$ & $H_{90 t h}$ & $H_{\text {mean }}$ & $H_{\max }$ & $H_{\min }$ & $f_{\text {gap }}$ & LPI & intensity \\
\hline LAI & 1.00 & & & & & & & & \\
\hline$H_{\text {5oth }}$ & -0.14 & 1.00 & & & & & & & \\
\hline$H_{\text {9oth }}$ & -0.22 & 0.37 & 1.00 & & & & & & \\
\hline$H_{\text {mean }}$ & 0.19 & 0.12 & -0.23 & 1.00 & & & & & \\
\hline$H_{\text {max }}$ & 0.24 & 0.17 & -0.25 & 0.09 & 1.00 & & & & \\
\hline$H_{\text {min }}$ & -0.25 & 0.16 & -0.26 & 0.06 & 0.15 & 1.00 & & & \\
\hline$f_{\text {gap }}$ & -0.31 & 0.28 & 0.06 & -0.38 & -0.14 & 0.25 & 1.00 & & \\
\hline LPI & -0.52 & 0.29 & 0.09 & 0.63 & -0.05 & -0.23 & -0.08 & 1.00 & \\
\hline intensity & 0.43 & 0.16 & 0.08 & -0.33 & -0.18 & -0.29 & 0.13 & 0.45 & 1.00 \\
\hline
\end{tabular}

trol of roll and lateral roll were able to achieve a high precision.

In the study area, numerous forest gaps are highly covered by low shrubs and grass, the spectrum characteristics of which are similar to certain forest pixels. The spectrum matching between the training and reference samples will be affected inevitably while the classification accuracy will be decreased when these pixels are mistakenly selected as the training samples. In addition, some similar objects have different spectra. The Hyperspectral image was then masked with three dimensional vertical structural information derived from Lidar, Therefore, the mutual interferences of the forest gaps and the tree species spectra with different heights were eliminated, and the extraction accuracy of the training samples correspondingly increased.

\section{Algorithm and model}

In the study, the plots are selected based on the LiDAR data coverage. According to the methods above, four circular plots data were collected, a few forest variables were calculated based on the investigated data. retrieve the fractional cover of forest by the grid. The test samples are used to validate and evaluate the accuracy of the models, and the best estimation model is selected. The LAI is inversed based on the best model. The experiment confirmed that Hyperspectral remote sensing images could express the spatial distribution and growth by estimating and monitoring LAI accurately and quickly within a large area. In study area, Pixel unmixing results is shown in Fig.5

For most of plants, the leaf area increases with the plant height during the vegetation growth. For different species and varieties of crops, the relationships of conversion between crop height, fraction of coverage and LAI was

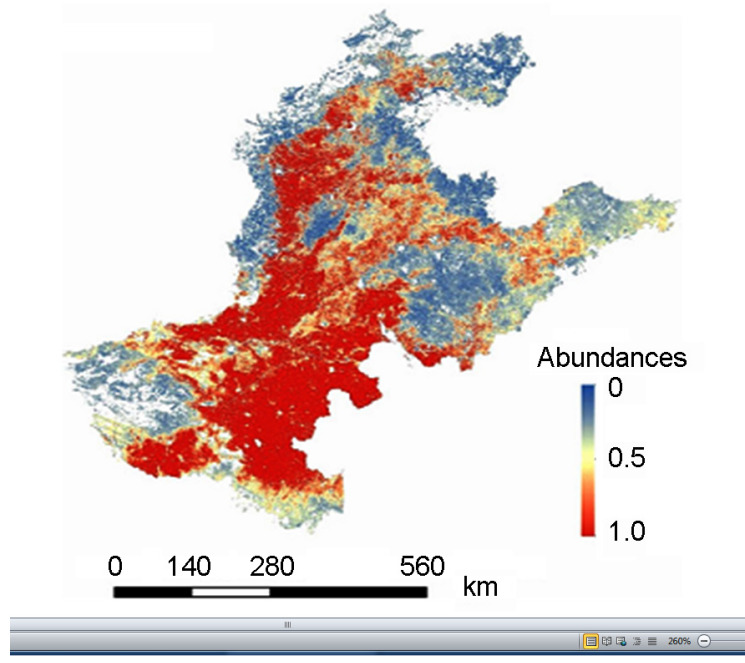

Fig.5.

proposed by Zhang (1996). Data classification and extraction of vegetation and ground point under different scales of a number of ground points and vegetation points. Finally calculate the laser radar penetration index and inversion calculation on LAI. The sampling data, LPI were calculated for each sample under various scales, LPI is laser penetrate index:

$$
L=-\frac{1}{k} \ln \left(\frac{I}{I_{0}}\right)=-\frac{1}{k} \ln (L P I)
$$

Where $L$ stand for the leaf area index, $I$ stands for the canopy light intensity, $I_{0}$ is above the canopy light intensity, $k$ is the extinction light coefficient, depending on the direction of the leaf inclination Angle and the beam of light, light beneath the canopy is available. LPI instead of $I / I_{0}$, (1/LPI) containing the intercept of the regression analysis with the measured LAI, 

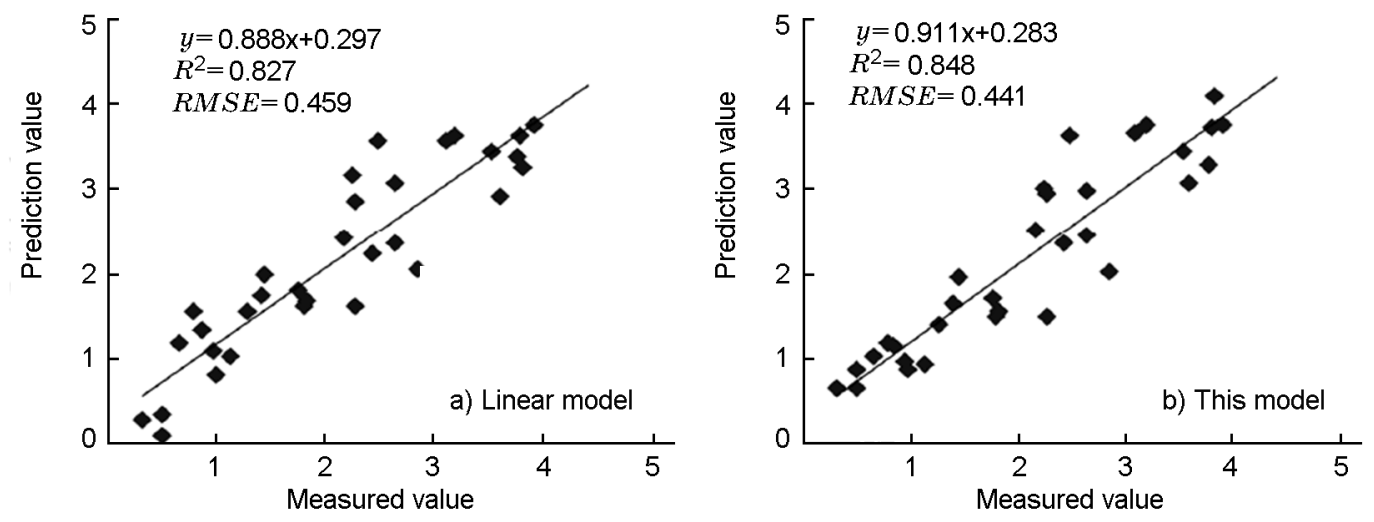

Fig.6 Prediction results for prediction samples of the this model and Linear model

inversion model based on the statistic analysis of the feature variables.

Found by different types of statistical regression models, these models have highest estimation accuracy is 90 percent in all models, the exponential regression model is the best model, using the model to invert maize leaf area index of the area and analysis its growth and space distribution. It is feasible to quantitative estimate the LAI values in a wide range fast and accurately using Hyperspectral remote sensing image.

The feature variables of LiDAR include: canopy height model (CHM), intensity , the mean height $\left(H_{\text {mean }}\right)$, the maximum height $\left(H_{\text {max }}\right)$, the minimum height $\left(H_{\min }\right)$, the percentile of the canopy height distributions $\left(H_{25 t h}, H_{50 t h}, H_{90 t h}\right)$ and LPI. In order to establish the optimal model of LiDAR-LAI prediction, it select a high correlation between LAI and LiDAR parameters, and extract the LiDAR vertical structure parameters of the same location. and the measured LAI values for correlation analysis, if the correlation coefficient absolute value is greater than 0.3 , then select it as the input parameters, the Correlation of LiDAR metrics and field measured LAI results are shown in Table1.

According to the results of correlation analysis in table 1 , then select the $f_{\text {op }}$,intensity, LPI, $H_{90 t h}$ as input variables for LiDAR-LAI estimation model. By the prior knowledge, LPI is inversely proportional to LAI, The value is larger, the smaller the leaf area index, according to the penetration index Formula, vegetation canopy echo is large, forest canopy structure is complex, the smaller the LPI. LAI is larger, therefore the LPI is negatively correlated with LAI; The greater the of $f_{g a p}$ vegetation, namely Coverage is lower, the smaller LAI; the intensity is larger Area, the larger LAI. the intensity of point cloud was positively related with LAI.

The above four LiDAR parameters as variables, multiple regression model is established. Through regression analysis with the above four LiDAR parameters, the inversion model was constructed by the regression model is depicted as:

$$
\begin{aligned}
L A I & =5.34+4.34 I-0.05 f_{p a p}- \\
& -1.78 L P I+0.03 \mathrm{H}_{90 \text { th }}
\end{aligned}
$$

Based on LiDAR_Pro,TerraScan,matlab200 9a,Erdas Imagine 9.2, The system runs on Windows7 operating system. In order to quantitatively evaluate the LAI result, contrasting the simulated data for the classic model, tests them in the same conditions, aiming to evaluate the results. It carries on the regression analysis and the measured LAI, calculate the value of correlation coefficient $\left(\mathrm{R}^{2}\right)$ and root mean square error (RMSE), High $\mathrm{R}^{2}$ indicates the high correlation between variables and independent variables. Through the above inversion method, Prediction results for prediction samples of the this model and Linear model is shown in Fig.6 , it can be seen that the inversion result of forest coverage was consistent with the vegetation distribution in Based on LiDAR_Pro,T erraScan,matlab2009a,Erdas Imagine9.2, The system runs on Windows 7 operating system. In order to quantitatively evaluate the LAI result, contrasting the simulated data for the classic model, tests them in the same conditions, aiming to evaluate the results. It carries on the regression analysis and the measured LAI, calculate the value of correlation coefficient $\left(\mathrm{R}^{2}\right)$ and root mean square error (RMSE), High $\mathrm{R}^{2}$ indicates the high correlation between variables and independent variables. Through the above inversion method, Prediction results for prediction samples of the this model and Linear model is shown in Fig. 6 , it can be seen that the inversion result of forest coverage was consistent with the vegetation distribution in the study area. Comparisons of LAI between those derived from Lidar and field measurements ( Table.2), it is showed that the LAI of Lidar and 
Zuowei Huang et al. / The novel method for LAI inversion ...

Tab. 2 Comparisons of LAI between those derived from Lidar and field measurements

\begin{tabular}{|c|c|c|c|c|c|c|}
\hline \multirow{2}{*}{ Plots } & \multicolumn{2}{|c|}{ Lidar results } & \multicolumn{2}{c|}{ Field measurements } & \multirow{2}{*}{$\begin{array}{c}\text { Absolute } \\
\text { error }\end{array}$} & $\begin{array}{c}\text { Relative } \\
\text { error/\% }\end{array}$ \\
\cline { 2 - 6 } & Average & $\begin{array}{c}\text { Standard } \\
\text { dev`iation }\end{array}$ & Average & $\begin{array}{c}\text { Standard } \\
\text { deviation }\end{array}$ & 0.036 & 0.449 \\
\hline 1 & 0.324 & 0.256 & 0.046 & 0.048 & 0.002 & 0.856 \\
\hline 2 & 0.342 & 0.036 & 0.678 & 0.003 & 0.045 & 1.533 \\
\hline 3 & 0.257 & 0.132 & 0.633 & 0.065 & 0.054 & 8.260 \\
\hline 4 & 0.323 & 0.022 & 0.418 & 0.036 & & 0.045 \\
\hline
\end{tabular}

filed data agree well, and only that the $3^{\text {th }}$ plot has a relative large error. The retrieval error of fractional cover will transfer to LAI. Results show that based on airborne and spaceborne LiDAR data LAI inversion accuracy is higher than that of the corresponding optical remote sensing inversion accuracy.

Based on LiDAR_Pro,TerraScan,matlab200 9a,Erdas Imagine9.2, The system runs on Windows 7 operating system. In order to quantitatively evaluate the LAI result, contrasting the simulated data for the classic model, tests them in the same conditions, aiming to evaluate the results. It carries on the regression analysis and the measured LAI, calculate the value of correlation coefficient (R2) and root mean square error (RMSE), High R2 indicates the high correlation between variables and independent variables. Through the above inversion method, Prediction results for prediction samples of the this model and Linear model is shown in Fig.6 ,it can be seen that the inversion result of forest coverage was consistent with the vegetation distribution in the study area. Comparisons of LAI between those derived from Lidar and field measurements ( Table.2), it is showed that the LAI of Lidar and filed data agree well, and only that the $3^{\text {th }}$ plot has a relative large error. The retrieval error of fractional cover will transfer to LAI. Results show that based on airborne and spaceborne LiDAR data LAI inversion accuracy is higher than that of the corresponding optical remote sensing inversion accuracy.

from Lidar and field measurements (Table.2), it is showed that the LAI of Lidar and filed data agree well, and only that the $3^{\text {th }}$ plot has a relative large error. The retrieval error of fractional cover will transfer to LAI. Results show that based on airborne and spaceborne LiDAR data LAI inversion accuracy is higher than that of the corresponding optical remote sensing inversion accuracy.

In order to evaluate the reliability of this inversion method, using leave-one-out cross-validation method, predicted LAI was evaluated by using 30 measured LAI data, it was showed that the determination coefficient is 0.8948 , the

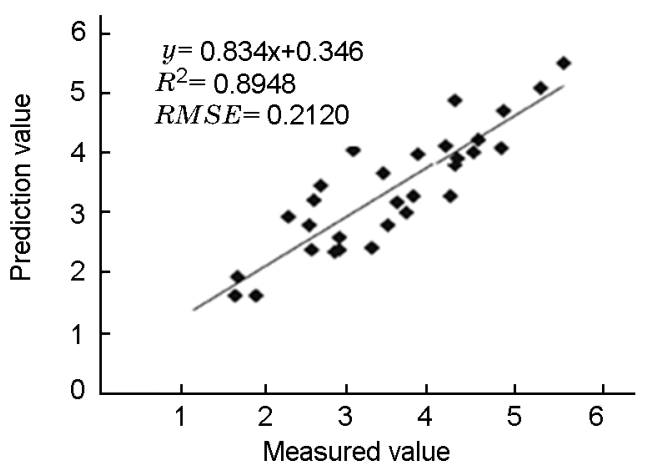

Fig.7 The relationship of measured value and Predicted value

root mean square error is 0.2120 towards measured value and predicted values(Fig.7), it found that the results of forest LAI joint inversion model was consistent with the distribution of forest type map. Hence, these results can be better applied to the quantitative inversion of LAI parameters.

\section{Conclusion}

LAI is a critical parameter in process-based models of vegetation canopy response to global environmental change, for numerous studies of interaction of atmosphere and vegetation, rapid, reliable and objective estimations of LAI are essential. It is feasible to quantitative estimate the LAI values in a wide range fast and accurately using Hyperspectral remote sensing image. The study about monitoring food crops using remote sensing in theories and applications is promoted, and the basic theories of monitoring and assessing LAI are supplied by it. In the case that remote sensing becoming more popular, the LiDAR technology has increasingly being used in the forestry as a new means of remote sensing. Many researchers have focused on LAI estimation using LiDAR data and explored the method of LAI retrieval based on LiDAR data and Hyperspectral data. In the future, Lidar will have extensive applications for precision agriculture and other agricultural production. In subsequent studies,other tech- 
niques for feature extraction will be tested to increase the LAI retrieval value, Results show that retrieving fractional cover and LAI with high accuracy and resolution is possible using the Lidar data and Hyperspectral data. In the future, Lidar will have extensive applications for precision agriculture and other agricultural production.

\section{Acknowledgment}

This work is supported by Natural Science Fund of Hunan Province(2017JJ2072)

\section{References}

1. Jianxi Huang, Yuan Zeng, Andres Kuusk et al., Int. J. Rem. Sens., 32(22), 7591, 2011.

2. Zhiqiang Xiao, Shunlin Liang, Jindi Wang, et al., Rem. Sens. Environ., 115, 97, 2011

3. Sprintsin M, Cohen S, Maseyk K, et al., Agric For Meteorol, 151(5), 565, 2011.

4. Majasalmi T, Rautiainen M, Stenberg P, et al. Agric For Meteorol, 154/155(3), 38, 2012.

5. Kauwe M G, Disney M I, Quaife T, et al., Rem. Sens. Environ., 115(2), 767, 2011.

6. Gonzalez-Sanpedro M C, Toan T L, Moreno J, et. al., Rem. Sens Environ, 112(3): 810, 2008.
7. Zhang L P and Huang X., J. Rem. Sens., 13(4), 559, 2011.

8. Zhong J Q and Wang R S. J. Rem. Sens., 27(10): 2055, 2006.

9. Bruzzone L, Chi M, Marconcini M. A, IEEE Trans. Geoscie. Rem. Sens., 44(11), 3363, 2006.

10. Chen Chong, Zhu Yanjun, Li Xianfeng, et al. Acta Agricul. Univ. Jiangxiensis, 33(3), 508, 2011.

11. Brantley S T, Zinnert J C, Young D R., Rem. Sens Environ, 115(2), 514, 2011.

12. Cheng Q, Huang J F, Wang R C and Tang Y L, Trans. Chinese Soc. Agricult. Eng., 19(5),104, 2013.

13. Clevers J G P W., Rem. Sens Environ, 29(1), 25, 2012.

14. Morsdorf F, Frey O, Meier E, et al., Int. J. .Rem. Sens., 29(5), 1387, 2008.

15. Pang Y, Zhao F, Li Z Y, Zhou S F, Deng G, Liu Q W and Chen E X., J. Rem. Sens., 12(1), 152, 2008.

16. Zeng Q H, Mao J H, Li X H and Liu X F. 2008. Geomat.Inform. Scienc. Wuhan Univ., 33(1), 25, 2008.

17. Zhang Y, Meng Q Y, Wu J L, Zhao F., Spectr. Spectr.Anal., 31 ( 10 ), 2789, 2011.

18. Zeng Q H, Mao J H, Li X H, Liu X F., Geom.. Inform. Scien. Wuhan Univ., 33(1), 25, 2008.

19. Madugundu R, Nizalapur V, Jha C S., Int J Appl Earth Obs Geoinf, 10(2), 211, 2008.

20. Potithep S, Nagai S, Nasahara K N, et al., , Agric For Meteorol, 169(2), 148, 2013.

21. Zarate-Valdez J L, Whiting M L, Lampinen B D, et al., Comput Electron Agr, 85(1), 24, 2012.

22. Luo Shezhou, Cheng Feng, Wang Fang, et al. Rem. Sens. Techn. Appl., 27(5), 740, 2012.

23. Heiskanen J, Rautiainen M, Korhonen L, et al. Int J Appl Earth Obs Geoinf, 13(4), 595, 2011. 